\title{
Pulmonary melioidosis in a patient with diabetes mellitus
}

\author{
I R VING CHOFNAS \\ Pulmonary Disease Section, Pulmonary Function Laboratory, and Inhalation Therapy Clinic, \\ Veterans Administration Center, Martinsburg, West Virginia 25401, U.S.A.
}

\begin{abstract}
A 32-year-old male diabetic developed an acute episode of progressive pulmonary melioidosis while employed in Vietnam. Ketosis and undue glycosuria frequently noted in diabetics with other acute infections were not recognized in this patient. The patient's response to combined and long-term antimicrobials was excellent. This approach to therapy is recommended in acute cases and refractory cases of chronic disease.
\end{abstract}

Melioidosis is a disease endemic in south-east Asia. It has achieved increased recognition in the United States since our participation in the Vietnam conflict and merits our enhanced interest (Gilbert, Moore, Hedberg, and Sanford, 1968).

\section{CASE REPORT}

A 32-year-old aircraft employee was admitted to the Veterans Administration Hospital, Martinsburg, West Virginia, on 24 July 1969 as a transfer from a service hospital in Vietnam. His military service in 1961 included sporadic trips to southeast Asia. Diabetes mellitus was diagnosed in 1962 and for several years was under control with 40 units of NPH insulin daily. He spent the last six months of 1968 as a civilian employee of an aircraft corporation in Vietnam. Six months later, in June 1969, he returned to the same work in the same area.

Onset of the present illness began one week after his return with an episode of diarrhoea lasting one week. This was followed by a few days of sweats, chills, fever, weakness, and cough productive of greenish-yellow sputum. The patient was admitted to a service hospital on 11 July 1969 , and 13 days later transferred to this hospital. Night sweats, haemoptysis, and foul sputum were denied. There had been a $15 \mathrm{lb}(6.8 \mathrm{~kg})$ weight loss but neither undue hyperglycaemia nor ketosis was noted.

The radiographic course was initially progressive, reaching a peak by 29 July 1969 when a loculated abscess was evident in the left upper lobe (Figure). It then regressed with therapy. Laboratory studies on admission revealed a white blood count of 13,000 and a haematocrit of 41 . Multiple $\overrightarrow{0}$ blood cultures were negative. Tuberculin tests, N intermediate and second strengths, and fungal serologies for blastomycosis, histoplasmosis, and coccidioidomycosis were negative.

Admission therapy consisting of procaine peni-à cillin, 600,000 units twice daily, failed to alter the daily temperature levels of between $102^{\circ}$ and $103^{\circ}$ F. On 29 July 1969 a report from the serviceo hospital stated that Pseudomonas pseudomallei was recovered from the patient's sputum. Drug susceptibility studies of this organism are noted (Table I). The patient was afebrile three days after the start of intravenous chloramphenicol, kanamycin, and tetracycline therapy as recommended by Weber, Douglass, Brundage, and Stall--3 kamp (1969). The last positive sputum culture wasio obtained on 28 August 1969.

\section{T A B LE I}

ANTIMICROBIAL SUSCEPTIBILITY OF ORIGINAL CULTURE-

\begin{tabular}{|c|c|}
\hline Drug & Response \\
\hline $\begin{array}{l}\text { Penicillin } \\
\text { Ampicillin } \\
\text { Streptomycin } \\
\text { Tetracycline } \\
\text { Chloramphenicol } \\
\text { Cephalothin } \\
\text { Hexamine } \\
\text { Kanamycin } \\
\text { Colistin sulphate } \\
\text { Neomycin }\end{array}$ & $\begin{array}{l}\text { Resistant } \\
\text { Resistant } \\
\text { Resistant } \\
\text { Sensitive } \\
\text { Sensitive } \\
\text { Resistant } \\
\text { Sensitive } \\
\text { Sensitive } \\
\text { Resistant } \\
\text { Resistant }\end{array}$ \\
\hline
\end{tabular}

Peripheral neuropathy attributable to chlor $\stackrel{\mathbb{D}}{\mathscr{D}}$ amphenicol was noted on 28 August 1969, an resolved one month after this drug was stoppedo 


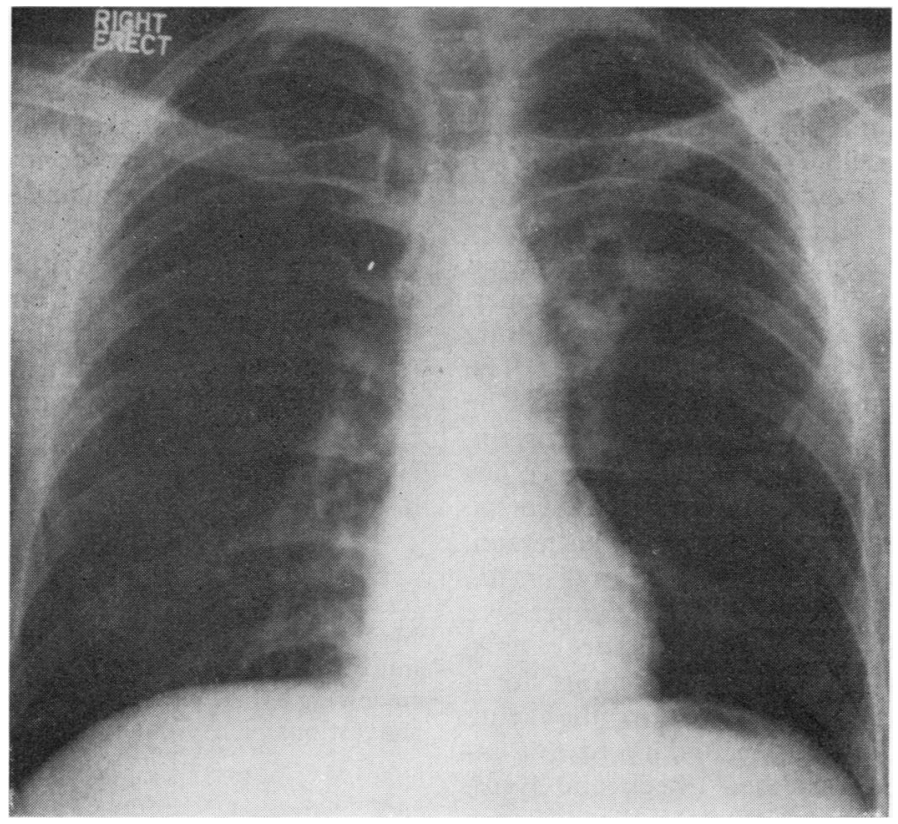

FIGURE. Chest radiograph at initiation of therapy.

At the completion of kanamycin therapy haematuria (100 red cells per high-power field) was noted. This regressed by 23 September 1969. On 9 November 1969, the patient's sole antimicrobial therapy was tetracycline, $250 \mathrm{mg}$ four times a day. This therapy was maintained for a period of three months after his discharge on 16 December 1969. He was asymptomatic when last seen on 2 June 1970. Periodic haemagglutination and complement fixation titres from 31 July 1969 to 2 June 1970 are reported (Table II).

\section{T A B L E I I}

SERIAL SEROLOGICAL TITRES FOR MELIOIDOSIS

\begin{tabular}{c|rr|c}
\hline $\begin{array}{c}\text { Haemagglutination } \\
\text { Titre }\end{array}$ & Date & $\begin{array}{c}\text { Complement Fixation } \\
\text { Titre }\end{array}$ \\
\hline $1 / 5120$ & 1969 July & 31 & $1 / 256$ \\
$1 / 5120$ & Oct & 10 & $1 / 64$ \\
$1 / 2560$ & Oct & 22 & $1 / 64$ \\
$1 / 1280$ & Nov & 25 & $1 / 64$ \\
$1 / 1280$ & 1970 Oct & 1 & $1 / 64$ \\
$1 / 1280$ & June & 2 & $1 / 16$ \\
\hline
\end{tabular}

DISCUSSION

Whitmore and Krishnaswami (1912) originally described melioidosis in 1912. The aetiologic agent is Ps. pseudomallei (Malleomyces pseudomallei), a bipolar pleomorphic Gram-negative rod (Baumann and Morita, 1967 ; Green and Tuffnell,
1968) said to be related to Malleomyces mallei, the causative organism in glanders. Ps. pseudomallei is harboured in the soil, vegetation, and water in the rice-growing areas in south-east Asia (Strauss, Groves, Mariappan, and Ellison, 1969b). Transmission to man is said to be direct from these areas. Laboratory transmission has been described (Green and Tuffnell, 1968). Man-to-man transmission has not been recorded but probably merits further scrutiny specifically in areas where the geographic history may be important in the differential diagnosis, such as the United States. Melioidosis has been found to be endemic in parts of the world other than south-east Asia (Rubin, Alexander, and Yager, 1963). Melioidosis reported from the United States, France, England, Africa, India, and Guam has been in soldiers who served in south-east Asia. There are reports of endemic cases originating in Ceylon, Burma, Java, Malaya, the Celebes, North Queensland, Australia, and the Panama Canal Zone (Rubin et al., 1963).

The skin and the respiratory tract are the original sites of patient infection. The clinical status of chronic melioidosis has been likened to tuberculosis and other granulomatous states. Haemagglutination and complement fixation titres for melioidosis may be positive without other clinical evidence of the disease (Nigg, 1963; 
Strauss et al., 1969a). In veterans returning with this disease it is most likely to be found in the chronic form (Spotnitz, Rudnitzky, and Rambaud, 1967). The disease may evidence itself as an asymptomatic state with pulmonary findings or with the presence of fever, cough, sputa, and slow progression of disease. Acute pulmonary melioidosis is marked by severe toxicity and rapid progression (Prevatt and Hunt, 1957; Cooper, 1967; Sheehy, Deller, and Weber, 1967; Spotnitz et al., 1967; and Weber et al., 1969). The septicaemic or haematogenous form may be secondary to skin or pulmonary sites of origin. Subsequent involvement of most of the other organs has been noted (Baumann and Morita, 1967; Diamond and Pastore, 1967; Patterson, Darling, and Blumenthal, 1967; Sheehy et al., 1967; Weber et al., 1969). The impressive mortality figures associated with melioidosis have occurred in reports of its haematogenous form and to a somewhat lesser degree in the acute pulmonary phase. Urticaria secondary to this infection has also been described (Steck and Byrd, 1969). In appropriate circumstances the presence of haematogenous or acute or chronic pulmonary infection calls for the consideration of $P s$. pseudomallei as the aetiological agent. A geographic history, tuberculin and fungal skin tests, and fungal serologies are excellent screening points. Blood cultures should be performed for diagnostic and prognostic purposes and for a potential therapeutic approach. The organism is readily identifiable and should be readily cultured from the sputum. Where biopsy material is available it should be examined. Complement fixation and haemagglutination studies are diagnostic but their titres do not correlate with the severity of the disease. It should be noted that with prolonged treatment an impressive drop was noted in this patient's complement fixation titre.

The treatment of melioidosis needs clarification. There is ample evidence that large doses of tetracycline offer adequate therapy in the chronic phase of this illness and should suffice when the disease is recognized in the great majority of our Vietnam veteran population with melioidosis (Gilbert et al., 1968). Concern should also be given to specific organism susceptibility studies. Weber et al. (1969) reported nine consecutive cases of the more malignant, acute disease from Vietnam. Without the rather formidable therapy, such as was used in this patient, the first four patients in his series died and the last five recovered when it was applied. Diamond and Pastore (1967) confirm a similar picture.
When one reviews the literature there seems to be an overlapping of the symptomatology ascribed to acute and chronic melioidosis. This patient seems to have had a limited but progressive acute illness controlled by therapy. $f$ suggest that in similar situations combined therapy be used.

Rimington (1962) reports three cases of melioidosis in diabetics from North Queenslandw Crotty, Bromwich, Quinn, and Brotherton (1963) from Darwin, Australia report another case. Inx none of these patients nor in the present casev could marked aggravation of diabetes be corre lated with the presence of Ps. pseudomallei infec fr tion.

I wish to thank Howard A. Buechner, M.D., professor of medicine, Tulane University School of Medicine, and Chief, Medical Service, Veterans Ad ministration Hospital, New Orleans, Louisiana, for reviewing the paper and for his many helpfute suggestions.

\section{REFERENCES}

Baumann, B. B., and Morita, E. T. (1967). Systemic melioi dosis presenting as myocardial infarct. Ann. intern. Med. 67, 836.

Cooper, E. B. (1967). Special communication. Melioidosis $\overrightarrow{\vec{\sigma}}$ J. Amer. med. Ass., 200, 452.

Crotty, J. M., Bromwich, A. F., Quinn, J. V., and Brotherton J. (1963). Melioidosis in the northern territory. A repor of two cases. Med.J. Aust., 1, 274.

Diamond, H. S., and Pastore, R. (1967). Septic arthritis dus to Pseudomonas pseudomallei. Arthr. and Rheum., 10,459?

Gilbert, D. N., Moore, W. L., Hedberg, C. L., and Sanford J. P. (1968). Review. Potential medical problems ino personnel returning from Vietnam. Ann. intern. Med. 68, 662 .

Green, R. N., and Tuffnell, P. G. (1968). Laboratory acquire® melioidosis. Amer. J. Med., 44, 599.

Nigg, C. (1963). Serologic studies on subclinical melioidosis? J. Immunol., 91, 18.

Patterson, M. C., Darling, C. L., and Blumenthal, J. BO (1967). Acute melioidosis in a soldier home from Sout Vietnam. J. Amer. med. Ass., 200, 447.

Prevatt, A. L., and Hunt, J. S. (1957). Chronic systemiło melioidosis. Review of literature and report of a cas? with a note on visual disturbance due to chloramphenicolw Amer. J. Med., 23, 810.

Rimington, R. A. (1962). Melioidosis in North Queenslando Med. J. Aust., 1, 50.

Rubin, H. L., Alexander, A. D., and Yager, R. H. (1963) Melioidosis. A military medical problem? Milit. Med:, $128,538$.

Sheehy, T. W., Deller, J. J., and Weber, D. R. (1967) Editorial. Melioidosis. Ann. intern. Med., 67, 897.

Spotnitz, M., Rudnitzky, J., and Rambaud, J. J. (1967) Melioidosis pneumonitis. J. Amer. med. Ass., 202, 950?

Steck, W. D., and Byrd, R. B. (1969). Urticaria secondary pulmonary melioidosis. Arch. Derm., 99, 80. 
Strauss, J. M., Alexander, A. D., Rapmund, G., Gan, E., and Dorsey, A. E. (1969a). Melioidosis in Malaysia. III. Antibodies to pseudomonas pseudomallei in the human population. Amer. J. trop. Med., 18, 703.

Groves, M. G., Mariappan, M., and Ellison, D. W. (1969b). Melioidosis in Malaysia. II. Distribution of pseudomonas pseudomallei in soil and surface water. J. trop. Med. Hyg., 18, 698.
Weber, D. R., Douglass, L. E., Brundage, W. G., and Stallkamp, T. C. (1969). Acute varieties of melioidosis occurring in U.S. soldiers in Vietnam. Amer. J. Med., 46, 234.

Whitmore, A., and Krishnaswami, C. S. (1912). An account of the discovery of a hitherto undescribed infective disease occurring among the population of Rangoon. Indian med. Gaz., 47, 262. 